\title{
Changes in tyrosine hydroxylase gene expression in mesencephalic catecholaminergic neurons of immature and adult male rats perinatally exposed to cannabinoids
}

\author{
A. Bonnin ${ }^{\text {a }}$, R. de Miguel ${ }^{\text {a }}$, J.C. Rodríguez-Manzaneque ${ }^{\text {b }}$, J.J. Fernández-Ruiz ${ }^{\text {a,* }}$, \\ A. Santos ${ }^{b, *}$, J.A. Ramos ${ }^{a, *}$ \\ a Instituto Complutense de Drogodependencias, ' Departamento de Bioquímica, Facultad de Medicina, Unitersidad Complutense, \\ 28040 Madrid, Spain
}

Accepted 24 May 1994

\begin{abstract}
We have previously reported that the perinatal exposure of pregnant rats to cannabinoids affected the activity of tyrosine hydroxylase $(\mathrm{TH})$ in the striatum of their male offspring at peripubertal ages. In the present work, we examined whether this effect was accompanied by modifications in TH gene expression. The amount of TH-mRNA - measured by Northern blot analysis with a specific TH probe - in the mesencephalon of 15- and 20-day-old male rats perinatally exposed to hashish extracts was higher than that measured in aged-matched controls. No differences appeared at 30 and 40 days after birth, a priori because they correspond to ages after the hashish withdrawal occurring on day 24 after birth. However, a significant decrease in the amount of TH-mRNA was observed in adult animals ( 70 days of life) perinatally exposed to hashish. The increase in TH-mRNA concentrations observed in hashish-exposed 15-day-old animals corresponded to an increase in the amount of TH protein, measured by Western blot analysis, in the mesencephalon, with no differences in the striatum. However, the amount of TH protein in both tissues was not modified by perinatal hashish treatment in adult animals, where TH-mRNA amounts had been decreased. In summary, perinatal cannabinoid exposure enhances the expression of the TH gene in mesencephalic catecholaminergic neurons during early peripubertal ages, coinciding with hashish treatment. Normality was found after hashish withdrawal and an interesting decrease in the amount of TH-mRNA appeared in adulthood, although with no reflection on the amount of TH protein.
\end{abstract}

Key words: Marihuana; Cannabinoid; Mesencephalic catecholaminergic neuron; Nigrostriatal dopaminergic neuron; Tyrosine hydroxylase; Tyrosine hydroxylase gene

We have recently reported that the development of nigrostriatal dopaminergic neurons is markedly affected by the perinatal exposure to the psychoactive constituents of Cannabis sativa derivatives (marihuana, hashish) $[9,10]$ (for a review, see [2]). This was to be expected because: (i) the striatum and the other basal ganglia of adult rats contain one of the highest densities of cannabinoid receptors [5], although they do not appear to be located in the nigrostriatal neurons but rather in their functionally related striatonigral GABAergic neurons [4]; (ii) we have recently described

\footnotetext{
* Corresponding authors. Fax: (34) (1) 3941691.
}

that these receptors are present from the early postnatal life in these brain areas [11]. Perinatal exposure to cannabinoids decreases the activity of tyrosine hydroxylase $(\mathrm{TH})$ in the rat striatum [10]. This effect was observed consistently throughout the peripubertal period (15-40 days after birth) [10] but only in males, in parallel with a decrease in spontaneous locomotor activity [2,9]. Both effects are partially normalized in adulthood, although certain behavioral and neurochemical alterations still remain at this age [9].

An interesting question emerges from these previous data: is the cannabinoid-induced decrease in the ontogeny of striatal $\mathrm{TH}$ activity accompanied by changes in the TH synthesis? To elucidate this question, pregnant rats were fed daily with hashish extract 
from day 5 of gestation until day 24 after birth and their male pups used at different immature ages and in adulthood to analyze TH gene expression. This was evaluated in the mesencephalon, the area where cell bodies for TH-containing striatal neurons, basically nigrostriatal dopaminergic neurons and other minor mesostriatal catecholaminergic neurons, are clustered, using Northern blot analysis with a specific $\mathrm{TH}$ probe. In addition, analyses of the amount of $\mathrm{TH}$ protein were also made, using Western blots, to correlate with mRNA changes. This was done not only in the mesencephalon but also in the striatum.

Animals, treatments and sampling. Female virgin rats of the Wistar strain were housed from birth in a room with controlled photoperiod $(08.00 \mathrm{~h}-20.00 \mathrm{~h}$ light) and temperature $\left(23 \pm 1^{\circ} \mathrm{C}\right)$. They had free access to standard food and water. At adult age ( $>8$ weeks of life; $150-200 \mathrm{~g}$ ), they were pregnant and used for the cannabinoid exposure studies. Hashish was obtained from the Spanish Administration. A crude extract was prepared in a sesame oil solution as previously reported [10] (it contained $14.5 \%$ of $\delta^{9}$-tetrahydrocannabinol (THC) and lesser percentages of other related cannabinoids). Pregnant females received a daily oral dose of hashish extract (equivalent to 20 $\mathrm{mg} / \mathrm{kg}$ THC daily) or vehicle from the 5 th day of gestation until day 24 after birth, the day on which the rats were weaned. Males born from these mothers were sacrificed at different immature ages $(15,20,30$ and 40 days after birth) and in adulthood (70 days after birth). Their brains were quickly removed and the mesencephalon and the striatum dissected [3] and immediately frozen at $-70^{\circ} \mathrm{C}$ until assayed.

RNA extraction and blot hybridization. Analysis of mRNA-TH concentrations from mesencephalic samples was done by using the method of RNA extraction described by Chomczynski and Sacchi [1] and a method of blot hybridization using a rat TH cDNA kindly supplied by Dr. Chikaraishi (Tufts University, Boston, MA, USA) [8] (see the legend to Fig. 1 for details). Values are the means \pm S.E.M. of at least four different samples.

Immunoblot analysis. Analysis of $\mathrm{TH}$ protein amounts was done according to the method described by Labatut et al. [7] using a monoclonal anti-TH antibody (see the legend to Fig. 2 for details). Values are the means \pm S.E.M. of at least four different blots.

Statistics. For data analysis, two-way analysis of variance (treatment-age), followed to an appropriate posthoc analysis, were used.

The postnatal ontogeny of TH-mRNA levels in the mesencephalon of the control male rats followed a typical pattern. In this sense, we found a progressive increase as from day 15 , reaching a maximum on day
A

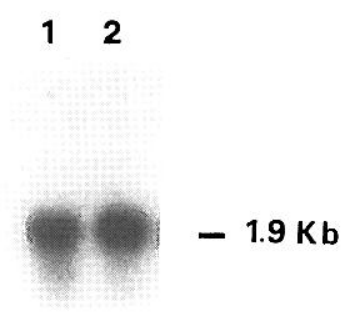

B

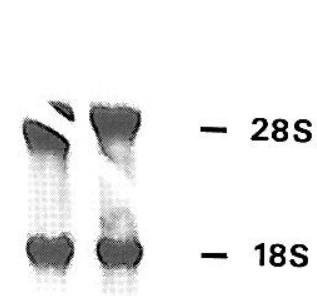

A

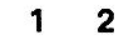

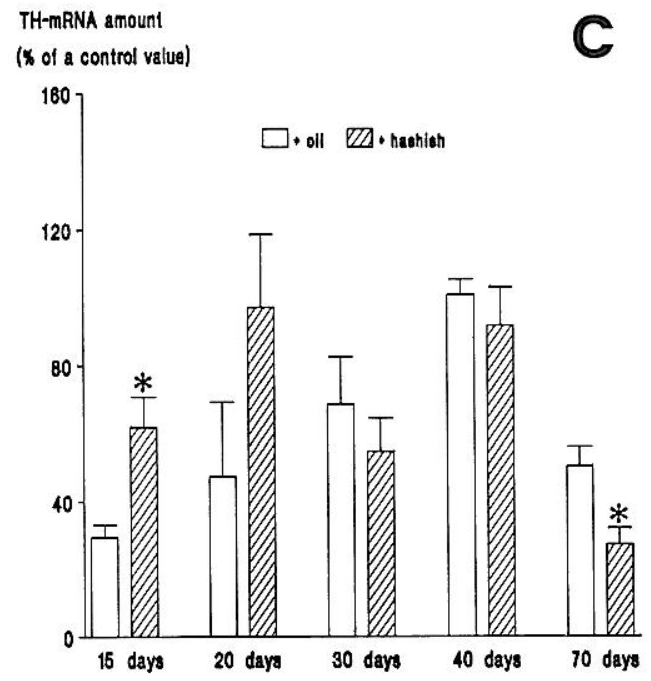

Fig. 1. Effects of perinatal cannabinoid exposure on TH-mRNA concentrations in the mesencephalon of immature and adult male rats. A: Northern blot analyses, showing the $1.9 \mathrm{~kb}$ band corresponding to TH-mRNA, of total RNA extracted from the mesencephalon of perinatally hashish-exposed male rats at different ages after birth selected from the most representative. Total RNA was probed with a $\left.{ }^{32} \mathrm{P}\right]-\mathrm{TH}-\mathrm{cDNA}$ using previously published [12] conditions of hybridization and washing. Blots were exposed to X-ray films and the autoradiograms quantitated by computer-assisted videodensitometry. As a control, $20 \mu \mathrm{g}$ of total RNA from a pool of rat adrenal glands were run in each gel and the densitometric values referred to it. Every age corresponded to different blots wi in a different control signal as revealed by the different rRNA signals in the Methylene blue stain. B: Methylene blue stain of the membranes after transfer, in which the positions of $18 \mathrm{~s}$ and $28 \mathrm{~s}$ rRNA are indicated. Left blot: oil-exposed 15-day-old males (lane 1) and hashish-exposed 15-day-old males (lane 2); Right blot: oil-exposed 70-day-old males (lane 1) and hashish-exposed 70-day-old males (lane 2). C: TH mRNA concentrations in the mesencephalon of perinatally hashish-exposed male rats at different ages after birth. Values are expressed as percentages of a control value (total RNA from adrenal glands). They are presented as means \pm S.E.M. of at least four different determinations per group. ${ }^{*}$ Indicates $P<0.05$ according to two-way ANOVA (treatment: $F_{1,49}=3.08$, ns; age: $F_{4.49}=7.38, P<0.005$; interaction: $F_{4,49}=3.22, P<0.05$ ). 
40 and decreasing afterwards in adulthood (Fig. 1). This pattern was not similar to that observed in the amount of $\mathrm{TH}$ protein in the mesencephalon, where relatively similar values were found at 15,40 and 70 days of age (Fig. 2). This presumably indicates the existence of age-dependent changes in the regulation of $\mathrm{TH}$ gene expression at transcriptional or translational levels. In the striatum, the evolution of $\mathrm{TH}$ protein amounts also followed a particular pattern, exhibiting a progressive increase as from day 15 until adulthood (Fig. 2). Interestingly, this pattern is similar to that previously reported in the enzymatic activity of $\mathrm{TH}$ in the striatum of control animals [10].

These patterns, especially in the mesencephalon, were markedly modified by perinatal hashish treatment. The effects of the treatment always depended on age as revealed the two-way analysis of variance (see the legends to the corresponding figures). Thus, the amount of TH-mRNA in the mesencephalon of 15 and 20-day-old male rats perinatally exposed to hashish extracts was higher (110.2\% and $104.6 \%$, respectively) than that observed in aged-matched controls (Fig. 1). This difference was statistically significant in animals of 15 days of age, whereas the level of statistical significance was borderline in 20-day-old rats. We be- lieve that this latter aspect would be due to the existence of important individual differences at this age, as revealed the high S.E.M. of TH-mRNA values in both groups. The increase in the mesencephalic content of TH-mRNA at 15 days after birth was accompanied by a parallel increase $(81.8 \%)$ in the amount of $\mathrm{TH}$ protein measured by Western blots (Fig. 2). However, this increase was not seen in the striatum (Fig. 2). This could mean that in spite of the higher TH synthesis in the mesencephalon, where cell bodies of mesostriatal neurons are located, the axoplasmic transport of this protein to the striatal terminals was not correlatively increased or that the half-life of the protein in these terminals was correlatively decreased. However, the present results do not confirm that the augmented $\mathrm{TH}$ gene expression in the mesencephalon of hashish-exposed 15-day-old males is only circumscribed to mesostriatal dopaminergic neurons. Possibly, it could occur in other mesotelencephalic dopaminergic neurons as well as in other catecholaminergic neurons, whose cell bodies are also located in the mesencephalic area dissected in the present study. However, the densest population of $\mathrm{TH}$-containing cell bodies in the mesencephalon mostly corresponds to nigrostriatal and mesolimbic dopaminergic neurons. In this regard, we

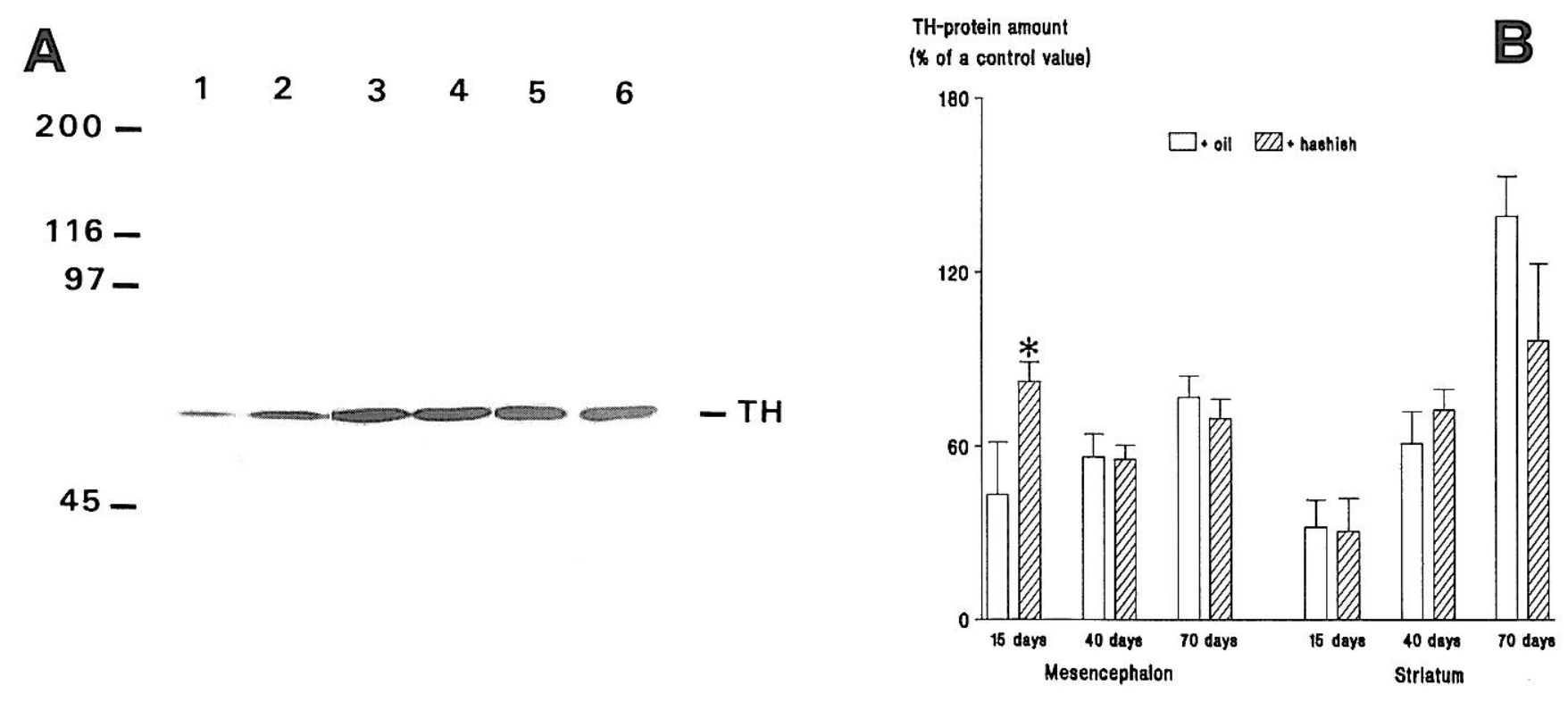

Fig. 2. Effects of perinatal cannabinoid exposure on the amount of TH protein in the mesencephalon and the striatum of immature and adult male rats. A: Western blot of total TH protein in the mesencephalon of perinatally hashish-exposed male rats at different ages after birth selected from the most representative. Tissues were subjected to previously published procedures of electrophoresis and immunolabelling [7]. Blots were exposed to X-ray films and developed under standard conditions. Films were quantitated by computer-assisted videodensitometry. As a control, a constant amount of total protein from a pool of rat striatal tissues was run in each gel and the densitometric values referred to it. The positions of molecular size markers (in kilodaltons) are shown. Lanes are: (1) oil-exposed 15-day-old males; (2) hashish-exposed 15-day-old males; (3) oil-exposed 40-day-old males; (4) hashish-exposed 40-day-old males; (5) oil-exposed 70-day-old males; and (6) hashish-exposed 70-days-old males. B: TH protein amounts in the mesencephalon and the striatum of perinatally cannabinoid-exposed male rats at different ages after birth. Values are expressed as percentages of a control value (total TH protein from striatal tissues). They are presented as means \pm S.E.M. of at least four different determinations per group. * Indicates $P<0.05$ according to two-way analysis of variance (mesencephalon: treatment: $F_{1,29}=3.74$, ns; age: $F_{2,29}=3.63, P<0.05$; interaction: $F_{2,29}=7.40, P<0.005$ ). 
have also found that $\mathrm{TH}$ protein amounts in the limbic forebrain were not affected by perinatal hashish exposure (data not shown).

Perinatal hashish treatment did not affect either the amounts of TH-mRNA in the mesencephalon of animals at 30 and 40 days of age (Fig. 1) or the amounts of $\mathrm{TH}$ protein in the mesencephalon and the striatum (Fig. 2) of 40-day-old rats. This could be related to the fact that these ages correspond to moments after hashish withdrawal. Because previous studies have indicated that THC and its metabolites disappear from the intact rat with a half-life of approximately 17 hours [6], it is unlikely that significant amounts of cannabinoids would have been present in the brain of the offspring at these ages and, of course, in adulthood. Hence, the effects on TH synthesis observed on day 15 after birth are acute and readily reversible and disappear after the drug withdrawal. However, an interesting decrease in the amount of TH-mRNA $(45.9 \%)$ was observed in adult males perinatally exposed to hashish (Fig. 1). This effect might represent a potential longterm effect caused by perinatal hashish exposure. However, the fact that this reduction was not accompanied by changes in amounts of TH protein either in the mesencephalon or in the striatum (Fig. 2) (a non-significant trend to decrease could be appreciated in the striatum) seems to indicate that it would be apparent only when faced with certain circumstances which might demand a higher dopamine synthesis with a possible requirement of de novo TH synthesis rather than in basal conditions.

In summary, perinatal cannabinoid exposure enhances the expression of the $\mathrm{TH}$ gene in mesencephalic catecholaminergic neurons during early peripubertal ages, coinciding with hashish treatment, whereas normality was found after hashish withdrawal and an interesting decrease, but only in the amount of TH-mRNA, appeared in adulthood.

This work was supported by two grants (OMFI: C180/91 and UCM: PR179/3527). Authors are indebted to Dr. Chikaraishi (Tufts University, Boston,
MA) for the gift of the TH probe and to the 'Servicio de Restricción de Estupefacientes y Psicótropos (Ministerio de Sanidad y Consumo, Madrid, Spain)' for the hashish supply.

[1] Chomczynski, P. and Sacchi, N., Single-step method of RNA isolation by acid guanidinium thiocyanate-phenol-chloroform extraction, Anal. Biochem., 162 (1986) 156-159.

[2] Fernández-Ruiz, J.J., Rodríguez de Fonseca, F., Navarro, M. and Ramos, J.A., Maternal cannabinoid exposure and brain development: changes in the ontogeny of dopaminergic neurons. In L.L. Murphy and A. Bartke (Eds.), Marihuana / Cannabinoids: Neurobiology and Neurophysiology, CRC Press, Boca Raton, FL, 1992, pp. 119-164.

[3] Glowinski, J. and Iversen, L.L., Catecholamine regional metabolism in rat brain, J. Neurochem., 13 (1966) 655-669.

[4] Herkenham, M., Lynn, A.B., de Costa, B.R. and Richfield, E.K., Neuronal localization of cannabinoid receptors in the basal ganglia of the rat, Brain Res., 547 (1991) 267-274.

[5] Howlett, A.C., Bidaut-Russell, M., Devane, W.A., Melvin, L.S., Johnson, M.R. and Herkenham, M., The cannabinoid receptor: biochemical, anatomical and behavioral characterization, TINS, 13 (1991) 420-423.

[6] Klausner, H.A. and Dingell, J.V., The metabolism and excretion of $\delta^{9}$-tetrahydrocannabinol in the rat, Life Sci., 10 (1971) 49-56.

[7] Labatut, R., Buda, M. and Bérod, A., Long-term changes in rat brain tyrosine hydroxilase following reserpine treatment: a cuantitative immunochemical analysis, J. Neurochem., 50 (1988) $1375-1380$

[8] Lewis, E.J., Harrington, C.A. and Chikaraishi, D.M., Transcriptional regulation of the tyrosine hydroxylase gene by glucocorticoid and cyclic AMP, PNAS (USA), 84 (1987) 3550-3554.

[9] Navarro, M., Rodríguez de Fonseca, F., Hernández, M.L., Ramos, J.A. and Fernández-Ruiz, J.J., Motor behavior and nigrostriatal dopaminergic activity in adult rats perinatally exposed to cannabinoids, Pharmacol. Biochem. Behai., 47 (1994) $47-58$.

[10] Rodríguez de Fonseca, F., Cebeira, M., Fernández-Ruiz, J.J., Navarro, M. and Ramos, J.A., Effects of pre- and perinatal exposure to hashish extracts on the ontogeny of brain dopaminergic neurons, Neuroscience, 43 (1991) 713-723.

[11] Rodríguez de Fonseca, F., Ramos, J.A., Bonnin, A. and Fernández-Ruiz, J.J., Presence of cannabinoid binding sites in the brain from early postnatal ages, Neuroreport, 4 (1993) 135138 .

[12] Santos, A., Freake, H.C., Rosenberg, M.E., Schwartz, H.L. and Oppenheimer, J.H., Triiodothyronine nuclear binding capacity in rat tissues correlates with a 6.0 kilobase $(\mathrm{kb})$ and not a $2.6 \mathrm{~kb}$ messenger ribonucleic acid hybridization signal generated by a human c-erbA probe, Mol. Endocrinol, 2 (1988) 992-998. 